\title{
Convergence Analysis for the Homotopy Perturbation Method for a Linear System of Mixed Volterra-Fredholm Integral Equations
}

\author{
Pakhshan Mohammedameen Hasan $^{1^{*}} \quad$ Nejmaddin Abdulla Sulaiman ${ }^{2}$
}

\author{
1,2 Department of Mathematics, College of Education, Salahaddin University-Erbil, Iraq. \\ *Corresponding author: pakhshansoran @ gmail.com , https://orcid.org/0000-0002-3243-0481 \\ ${ }^{2}$ gardy.muhamad@yahoo.com , https://orcid.org/0000-0002-3307-9451
}

Received 23/7/2019, Accepted 2/1/2020, Published 8/9/2020

This work is licensed under a Creative Commons Attribution 4.0 International License.

\begin{abstract}
:
In this paper, the homotopy perturbation method (HPM) is presented for treating a linear system of second-kind mixed Volterra-Fredholm integral equations. The method is based on constructing the series whose summation is the solution of the considered system. Convergence of constructed series is discussed and its proof is given; also, the error estimation is obtained. Algorithm is suggested and applied on several examples and the results are computed by using MATLAB (R2015a). To show the accuracy of the results and the effectiveness of the method, the approximate solutions of some examples are compared with the exact solution by computing the absolute errors.
\end{abstract}

Key words: Homotopy perturbation method, linear system of second kind mixed Volterra-Fredholm integral equations.

\section{Introduction}

In this work, the linear system of second kind mixed Volterra-Fredholm integral equations (LSMVFIE2 ${ }^{\text {nd }}$ ) will be considered which has the form:

$$
U(x)=F(x)+\lambda \int_{a}^{x} \int_{a}^{b} K(r, t) U(t) d t d r,
$$

where

$$
\text { for } a \leq x \leq b
$$

$$
\begin{gathered}
U(x)=\left[u_{1}(x), u_{2}(x), \ldots, u_{n}(x)\right]^{t}, \\
F(x)=\left[f_{1}(x), f_{2}(x), \ldots, f_{n}(x)\right]^{t}, \\
\lambda K(r, t)=\left[\lambda_{i j} k_{i j}(r, t)\right] . i, j=1,2, \ldots, n .
\end{gathered}
$$

In equation (1), the functions $f_{i}(x)$ are continuous on the interval $[a, b]$, and $k_{i j}(r, t)$ are continuous on $D=\{(r, t): t \in[a, b] \& a \leq r \leq x \leq b\}$, for $i, j=$ $1,2, \ldots, n$; while $U(x)$ are unknown continuous functions to be found.

Systems of integral equations have great importance in science and engineering. Recently, many methods have been used for solving them.
Ghasemi et al. presented an analytical treatment for linear system of Volterra-Fredholm integral equation by using the so called h-curves (1). Karimi and Jozi solved the system of Fredholm integral equations by Taylor series-expansion method (2). Wazwaz (3) also approximated the exact solution of system of Fredholm integral equations by the Adomian decomposition method. Alturk (4) used weighted mean-value theorem for solving Fredholm integral and integro differential equations and their system. By contrast, in (5) the improvement of block-pulse functions has been discussed by Mirzaee to solve system of linear Volterra and Fredholm integral equations. In addition, Hesameddini and Shahbazi solved system of Volterra-Fredholm integral equations with hybrid Bernstein Block pulse functions (6). In (7), Radzuan et al. treated the system of Fredholm integral equations by halve-sweep kaudd successive over relaxation iterative. While, Hameed et al. treated the system of nonlinear Volterra integral equations by the Newton-Kantorovich method (8). Finally, in (9) the approximate solution of system of nonlinear integral equations is discussed.

The Homotopy perturbation method (HPM) is a strong method in which the approximate solution is considered as a series solution which converges rapidly to the accurate approximation with a high 
accuracy. The method was proposed in 1998 by $\mathrm{He}$ (10) and was further developed and improved for solving nonlinear problem in (11) and (12). The convergence of HPM for Fredholm integral equations and Volterra integral equations of the second kind is discussed in (13). It has also been used to find approximate and exact solution for Volterra-Fredholm integro differential equations in (14), and their systems in (15), while in (16) the method is used for system of Burgers equations.

Presenting a convergence condition for HPM and the error estimation for the solution is our major purpose in this work.

\section{Application of HPM on LSMVFIE2 ${ }^{\text {nd }}$}

Recall system (1) and consider the $i^{\text {th }}$ equation of the system as

$$
\begin{gathered}
u_{i}(x)=f_{i}(x)+ \\
\sum_{j=1}^{n} \lambda_{i j} \int_{a}^{x} \int_{a}^{b} k_{i j}(r, t) u_{j}(t) d t d r .
\end{gathered}
$$

To illustrate HPM, define the operator $\ell_{i}$ as follows:

$$
\begin{aligned}
& \ell_{i}\left(u_{1}{ }^{*}(x), \ldots, u_{n}{ }^{*}(x)\right)=u_{i}{ }^{*}(x)-f_{i}(x) \\
& -\sum_{j=1}^{n} \lambda_{i j} \int_{a} \int_{a} k_{i j}(r, t) u_{j}{ }^{*}(t) d t d r=0,
\end{aligned}
$$

with the solution $u_{i}^{*}(x)=u_{i}(x)$. The homotopy perturbation method defines a convex function $H_{i}\left(u_{1}{ }^{*}(x), u_{2}{ }^{*}(x), \ldots, u_{n}{ }^{*}(x), p\right): \mathcal{R} \times[0,1] \rightarrow \mathcal{R}$ by

$$
\begin{aligned}
& H_{i}\left(u_{1}{ }^{*}(x), \ldots, u_{n}{ }^{*}(x), p\right)=(1-p) G_{i}\left(u_{i}{ }^{*}\right) \\
& +p \ell_{i}\left(u_{1}^{*}(x), \ldots, u_{n}{ }^{*}(x)\right)=0,
\end{aligned}
$$

where, $G_{i}\left(u_{i}^{*}\right)=u_{i}^{*}(x)-f_{i}(x)$ is a functional operator, $p \in[0,1]$ is the homotopy parameter, and let $u_{i 0}(x)$ be a known initial approximation of equation (1), $\operatorname{say}_{i}(x)$ for all $i=1,2, \ldots, n$.

From equation (4), we have

$$
\left.\begin{array}{l}
H_{i}\left(u_{1}^{*}(x), \ldots, u_{n}^{*}(x), 0\right)=G_{i}\left(u_{i}^{*}\right), \text { and } \\
H_{i}\left(u_{1}^{*}(x), \ldots, u_{n}^{*}(x), 1\right)=\ell_{i}\left(u_{1}^{*}, \ldots, u_{n}^{*}\right)
\end{array}\right\} .
$$

The proses of changing the imbedding parameter $p$ from 0 to 1 is just that of $H_{i}\left(u_{1}^{*}(x), \ldots, u_{n}{ }^{*}(x), p\right)$ from the trivial problem $H_{i}\left(u_{1}{ }^{*}(x), \ldots, u_{n}{ }^{*}(x), 0\right)=$ $G_{i}\left(u_{i}^{*}\right)=0$, to the original problem

$$
H_{i}\left(u_{1}^{*}(x), \ldots, u_{n}^{*}(x), 1\right)=
$$

$$
\ell_{i}\left(u_{1}^{*}(x), \ldots, u_{n}^{*}(x)\right)=0 .
$$

By using $\ell_{i}\left(u_{1}^{*}(x), \ldots, u_{n}^{*}(x)\right)$ and $G_{i}\left(u_{i}^{*}\right)$ defined above, the homotopy operator of the considered equation will be obtained:

$$
\begin{aligned}
& \left(u_{1}^{*}(x), \ldots, u_{n}^{*}(x), p\right) \\
& =(1-p)\left(u_{i}^{*}(x)-f_{i}(x)\right) \\
& +p\left(u_{i}^{*}(x)-f_{i}(x)\right. \\
& \left.-\sum_{j=1}^{n} \lambda_{i j} \int_{a}^{x} \int_{a}^{b} k_{i j}(r, t) u_{j}^{*}(t) d t d r\right) . \\
& i=1,2, \ldots, n
\end{aligned}
$$

Thus, for all $i$ we have

$$
\begin{gathered}
H_{i}\left(u_{1}^{*}(x), \ldots, u_{n}^{*}(x), p\right) \\
=u_{i}^{*}(x)-f_{i}(x) \\
-p\left(\sum_{j=1}^{n} \lambda_{i j} \int_{a}^{x} \int_{a}^{b} k_{i j}(r, t) u_{j}^{*}(t) d t d r\right)=0 .
\end{gathered}
$$

The method admits the use of a power series:

$$
u_{i}^{*}(x)=\sum_{j=0}^{\infty} p^{j} u^{*}{ }_{i j}(x) . \quad i=1,2, \ldots, n .
$$

If equation (7) has a radius of convergence that is $\nless$ 1 also, $\sum_{j=0}^{\infty} u^{*}{ }_{i j}(x)$ converges absolutely, then the approximation of equation (1) is found:

$$
\begin{aligned}
u_{i}(x) & =\lim _{p \rightarrow 1} \sum_{j=0}^{\infty} p u_{i j}^{j}(x) \\
& =\sum_{j=0}^{\infty} u^{*}{ }_{i j}(x), i=1,2, \ldots, n .
\end{aligned}
$$

Substituting (7) in equation (6) gives

$$
\begin{gathered}
\sum_{j=0}^{\infty} p^{j} u^{*}{ }_{i j}(x)=u_{i 0}(x) \\
+p\left(\sum_{j=1}^{n} \lambda_{i j} \int_{a}^{x} \int_{a}^{b} k_{i j}(r, t) \sum_{l=0}^{\infty} p^{l} u^{*}{ }_{j l}(x) d t d r\right) . \\
i=1,2, \ldots, n .
\end{gathered}
$$

by equating the similar power terms of $p$ gives a recurrence relations that leads to the approximate solution:

$$
p_{i}^{0}: u_{i 0}^{*}(x)=u_{i 0}(x)
$$




$$
\begin{aligned}
& p_{i}^{l}: u_{i l}^{*}(x) \\
= & \sum_{j=1}^{n} \lambda_{i j} \int_{a}^{x} \int_{a}^{b} k_{i j}(r, t) u_{j, l-1}^{*}(x) d t d r .
\end{aligned}
$$

for $l \geq 1$.

The above relations have been obtained by assuming that (7) is convergent. In the following Theorem, the conditions for such convergence will be discussed.

\section{Convergence Analysis}

Theorem3.1. Let the functions $k_{i j}$ and $f_{i}$ in system (1) be continuous in the specified domain that is $k_{i j} \in$ $C([a, b] \times[a, b])$ and $f_{i} \in C[a, b] \quad \forall i, j=1,2, \ldots, n$. If the following inequality

where

$$
n \beta(b-a)^{2}<1
$$

$$
\beta=\max _{i=1,2, \ldots, n}\left\{\left|\lambda_{i j}\right| \cdot\left(M_{i j}\right)\right\} \text {, for } j=1,2, \ldots, n
$$

satisfied, and $u_{i 0} \in C[a, b]$ are chosen as an initial solution, then for each $p \in[0,1]$, the series (7) converges uniformly in the interval $[a, b]$ in which the functions $u^{*}{ }_{i 0}$ and $u^{*}{ }_{i l}$ are found by equations (9) and (10), respectively.

Proof: Since $k_{i j}$ and $f_{i}$ are bounded for each $i, j=$ $1,2, \ldots, n$; then $\exists M_{i j}>0$ and $L_{i 0}$ such that

$$
\left|k_{i j}(x, t)\right| \leq M_{i j} \text {, and }\left|f_{i}(x)\right| \leq L_{i 0} \text {. }
$$

for $x, t \in[a, b]$

Let $u_{i 0}(x) \in C[a, b]$, then there exist positive numbers $L_{i 0}$ such that

$$
\left|u_{i 0}(x)\right| \leq L_{i 0}, \quad \forall x \in[a, b]
$$

Now, let

$$
\begin{aligned}
& L=\max _{i=1,2, \ldots, n} L_{i 0}, \\
& \text { and } \beta=\max _{i=1,2, \ldots, n}\left\{\left|\lambda_{i j}\right| \cdot\left(M_{i j}\right)\right\} \text {, for } j=1,2, \ldots, n .
\end{aligned}
$$

The above assumptions imply the estimations below:

$$
\left|u^{*}{ }_{i 0}(x)\right|=\left|u_{i 0}(x)\right| \leq L_{i 0} \leq L \text {. }
$$

$$
\begin{aligned}
& \left|u^{*}{ }_{i 1}(x)\right|=\left|\sum_{j=1}^{n} \lambda_{i j} \int_{a}^{x} \int_{a}^{b} k_{i j}(r, t) u^{*}{ }_{j 0}(x) d t d r\right| \\
& \leq \sum_{j=1}^{n}\left|\lambda_{i j}\right| \int_{a}^{x} \int_{a}^{b}\left|k_{i j}(r, t)\right|\left|u_{j 0}^{*}(x)\right| d t d r \\
& \leq \sum_{j=1}^{n}\left|\lambda_{i j}\right| M_{i j} \int_{a}^{x} \int_{a}^{b}\left|u^{*}{ }_{j 0}(x)\right| d t d r \\
& \leq \sum_{j=1}^{n} \beta \int_{a}^{x} \int_{a}^{b} L_{j 0} d t d r \\
& \leq n \beta L(b-a)^{2} \text {. } \\
& \left|u^{*}{ }_{i 2}(x)\right|=\left|\sum_{j=1}^{n} \lambda_{i j} \int_{a}^{x} \int_{a}^{b} k_{i j}(r, t) u^{*}{ }_{j 1}(x) d t d r\right| \\
& \leq \sum_{j=1}^{n}\left|\lambda_{i j}\right| M_{i j} \int_{a}^{x} \int_{a}^{b}\left|u^{*}{ }_{j 1}(x)\right| d t d r \\
& \leq \sum_{j=1}^{n} \beta \int_{a}^{x} \int_{a}^{b}\left(n \beta L(b-a)^{2}\right) d t d r \\
& \leq n^{2} \beta^{2}((b \\
& \left.-a)^{2}\right)^{2} L \text {. }
\end{aligned}
$$

general, we have In

$$
\begin{gathered}
\left|u_{i l}^{*}(x)\right|=\left|\sum_{j=1}^{n} \lambda_{i j} \int_{a}^{x} \int_{a}^{b} k_{i j}(r, t) u_{j, l-1}^{*}(x) d t d r\right| \\
\leq n^{l} \beta^{l}\left((b-a)^{2}\right)^{l} L . \quad l \geq 1
\end{gathered}
$$

In this way, for series (7), we have, for $p \in[0,1]$,

$$
\begin{aligned}
\sum_{j=0}^{\infty} p^{j} u_{i j}^{*}(x) & \leq \sum_{j=0}^{\infty}\left|u_{i j}^{*}(x)\right| \\
& \leq L\left(\sum_{j=0}^{\infty} n^{j} \beta^{j}\left((b-a)^{2}\right)^{j}\right) .
\end{aligned}
$$

Which is a geometric series, with the common ratio $r=n \beta(b-a)^{2}<1$, and it is convergent [by the assumption in equation (11)]. Consequently, series (8) converges uniformly in the interval $[a, b]$ for each $p \in[0,1]$. 
If it is impossible or difficult to calculate the series summation in (8), its partial sum can be accepted as an approximate solution of equation (1). In the limit $p \rightarrow 1$, terms of first $l+1$ in (8) produce $l$-th order approximate solution as

$$
\widehat{u}_{i l}(x)=\sum_{j=0}^{l} u^{*}{ }_{i j}(x), i=1,2, \ldots, n
$$

The level of error of the solution $\widehat{u}_{i n}(x)$ can be estimated by the following theorem:

Theorem3.2. Estimated error of the lth-order approximation will be determined as follows:

$$
\varepsilon_{i l} \leq L \frac{n^{l+1} \beta^{l+1}\left((b-a)^{2}\right)^{l+1}}{1-n \beta(b-a)^{2}} ; i=1,2, \ldots, n
$$

Where $\varepsilon_{i l}=\sup _{x \in[a, b]}\left|u_{i}(x)-\widehat{u}_{i l}(x)\right|, M_{i j}$, and $L_{i 0}$ are determined in theorem (3.1).

Proof: Using of estimations of functions $u_{i j}^{*}(x)$ gives

$$
\begin{aligned}
& \left|u(x)-\hat{u}_{i l}(x)\right|=\left|\sum_{j=0}^{\infty} u_{i j}^{*}(x)-\sum_{j=0}^{l} u_{i j}^{*}(x)\right| \\
& =\left|\sum_{j=l+1}^{\infty} u^{*}{ }_{i j}(x)\right|, \forall x \in[a, b] \\
& \leq \sum_{j=l+1}^{\infty}\left|u_{i j}^{*}(x)\right| \\
& \leq L\left(\sum_{j=l+1}^{\infty} n^{j} \beta^{j}\left((b-a)^{2}\right)^{j}\right) \\
& =L\left(n \beta(b-a)^{2}\right)^{l+1}\left\{1+n \beta(b-a)^{2}\right. \\
& \left.+\left(n \beta(b-a)^{2}\right)^{2}+\cdots\right\} \\
& =L \frac{\left(n \beta(b-a)^{2}\right)^{l+1}}{1-n \beta(b-a)^{2}} .
\end{aligned}
$$

Note: The above theorem can be considered as the rate of convergence of HPM, and its application can be considered in example 3 .

\section{The HPM Algorithm}

To find an approximate solution of (LSMVFIE2 ${ }^{\text {nd }}$ ) by HPM, perform the following steps:
Step 1: Choose the integers $n$ and $m$, and the bounds of integration $a$, and $b$.

Step 2: Let $u_{i 0}(x)=f_{i}(x)$ be an initial solution.

Step 3: Calculate $u^{*}{ }_{i l}(x)$ in equations (9-10) for all $i=1,2, \ldots, n$ and $l \geq 1$.

Step 4: Compute the partial sum $\widehat{u}_{i l}(x)=$ $\sum_{j=0}^{l} u^{*}{ }_{i j}(x) ; i=1,2, \ldots, n$ from equation (13).

Step 5: Find $\hat{u}_{i l}\left(x_{j}\right), x_{j} \in[a, b]$, where $x_{j}=$ $x_{0}+j h$, for $j=1,2, \ldots, m$ where $h=\frac{b-a}{m}$.

Step 6: Compute the absolute error of each $\operatorname{root}\left|u_{i}\left(x_{j}\right)-\hat{u}_{i l}\left(x_{j}\right)\right|$.

\section{Numerical Examples}

In this part, several examples will be solved to show the implementation of the method and its strength.

Example1. Consider the linear system of VolterraFredholm integral equations below:

$$
\left.\begin{array}{c}
u_{1}(x)=f_{1}(x)+ \\
\frac{1}{3} \int_{0}^{x} \int_{0}^{1} k_{11} u_{1}(t) d t d r+\frac{1}{4} \int_{0}^{x} \int_{0}^{1} k_{12} u_{2}(t) d t d r, \\
u_{2}(x)=f_{2}(x)+ \\
\frac{1}{5} \int_{0}^{x} \int_{0}^{1} k_{21} u_{1}(t) d t d r+\frac{1}{4} \int_{0}^{x} \int_{0}^{1} k_{22} u_{2}(t) d t d r,
\end{array}\right\}
$$

For $0 \leq x \leq 1$ where,

$$
\begin{aligned}
& f_{1}(x)=\frac{x}{3}+e^{x}-\frac{\left(x^{2}\left(\frac{e}{2}-\frac{1}{2}\right)\right)}{3}-\frac{x^{2}}{32}, \\
& f_{2}(x)=\frac{103 x^{2}}{120}-\frac{(x(e-1))}{5}, \\
& k_{11}=r-t, k_{12}=r t, k_{21}=r t+1, \text { and } k_{22}=r .
\end{aligned}
$$

The exact solutions are

$$
u_{1}(x)=e^{x}, u_{2}(x)=x^{2}
$$

First, it will be verified whether the described method can be used for solving this problem.

Since $k \in C([0,1] \times[0,1])$ and $f \in C([0,1])$, then we check the veracity of inequality (11).

this example In,

$\left|\lambda_{11}\right|=\frac{1}{3},\left|\lambda_{12}\right|=\frac{1}{4},\left|\lambda_{21}\right|=\frac{1}{5}$ and $\left|\lambda_{22}\right|=\frac{1}{4}$

Also, we have 


$$
\begin{aligned}
& M_{11}=\max _{r, t \in[0,1]}\left|k_{11}(r, t)\right|=1, \\
& M_{12}=\max _{r, t \in[0,1]}\left|k_{12}(r, t)\right|=1, \\
& M_{21}=\max _{r, t \in[0,1]}\left|k_{21}(r, t)\right|=2, \\
& \text { and } \quad M_{22}=\max _{r, t \in[0,1]}\left|k_{22}(r, t)\right|=1, \\
& n \beta(b-a)^{2}=\frac{4}{5}<1,
\end{aligned}
$$

where, $\beta$

$$
\begin{aligned}
& =\max .\left\{\left|\lambda_{11}\right| M_{11},\left|\lambda_{12}\right| M_{12},\left|\lambda_{21}\right| M_{21},\left|\lambda_{22}\right| M_{22}\right\} \\
& =\frac{2}{5}
\end{aligned}
$$

Now, let $u_{10}=f_{1}(x)$, and $u_{20}=f_{2}(x)$.

Then, the continuous functions $u_{1,0}{ }^{*}(x)$, and $u_{2,0}{ }^{*}(x)$, are selected in the interval $[0,1]$ as explained in equation (9)

$$
\begin{aligned}
& u_{1,0}^{*}(x)=u_{10}=\frac{x}{3}+e^{x}-\frac{\left(x^{2}\left(\frac{e}{2}-\frac{1}{2}\right)\right)}{3}-\frac{x^{2}}{32}, \\
& \text { and } u_{2,0}{ }^{*}(x)=u_{20}=\frac{103 x^{2}}{120}-\frac{(x(e-1))}{5} .
\end{aligned}
$$

While, the values of $u_{1, l}{ }^{*}(x)$ and $u_{2, l}{ }^{*}(x)$ for $l \geq 1$ will be determined using equation (10).

Thus

$$
\begin{aligned}
\hat{u}_{1,1}(x)= & -0.008614448834 x^{2} \\
& -0.010567844975 x+e^{x} \\
\hat{u}_{2,1}(x)= & 0.975789052859 x^{2} \\
& +0.012157979683788 x \\
\hat{u}_{1,2}(x)= & -0.001609243850 x^{2} \\
& +0.001892075733 x+e^{x} \\
\hat{u}_{2,2}(x)= & 0.999183461546 x^{2} \\
& -0.001631081086 x \\
\hat{u}_{1,3}(x)= & -0.000025207997 x^{2} \\
& -0.00007612698 x+e^{x} \\
\hat{u}_{2,3}(x)= & 0.999886873091 x^{2} \\
& +0.00008192465 x
\end{aligned}
$$

\begin{tabular}{|c|c|c|}
\hline$x_{j}$ & $\begin{array}{l}\text { Absolute error of } u_{1} \\
\left|u_{1}\left(x_{j}\right)-\widehat{u}_{1,10}\left(x_{j}\right)\right|\end{array}$ & $\begin{array}{l}\text { Absolute error of } u_{2} \\
\left|u_{2}\left(x_{j}\right)-\widehat{u}_{2,10}\left(x_{j}\right)\right|\end{array}$ \\
\hline 0 & 0 & 0 \\
\hline 0.1 & $1.9184653866 \mathrm{e}-13$ & $1.8479315304 \mathrm{e}-13$ \\
\hline 0.2 & $3.6215475063 \mathrm{e}-13$ & $3.6668584835 \mathrm{e}-13$ \\
\hline 0.3 & $5.1025850212 \mathrm{e}-13$ & $5.4567461660 \mathrm{e}-13$ \\
\hline 0.4 & $6.3660188232 \mathrm{e}-13$ & $7.2178374388 \mathrm{e}-13$ \\
\hline 0.5 & $7.4096284663 \mathrm{e}-13$ & $8.9497853573 \mathrm{e}-13$ \\
\hline 0.6 & $8.2356343967 \mathrm{e}-13$ & $1.0652589921 \mathrm{e}-12$ \\
\hline 0.7 & $8.8373752760 \mathrm{e}-13$ & $1.2326251131 \mathrm{e}-12$ \\
\hline 0.8 & $9.2281737807 \mathrm{e}-13$ & $1.3972156765 \mathrm{e}-12$ \\
\hline 0.9 & $9.3880458962 \mathrm{e}-13$ & $1.5588641489 \mathrm{e}-12$ \\
\hline 1 & $9.3391960831 \mathrm{e}-13$ & $1.7174039968 \mathrm{e}-12$ \\
\hline
\end{tabular}

The absolute errors for the approximate solutions $\widehat{u}_{1,10}(x)$ and $\hat{u}_{2,10}(x)$ at distinct values of $x$ are presented in Table 1. Also, Fig.1 shows the convergence of the method for $\hat{u}_{1, l}(x)$ and $\widehat{u}_{2, l}(x)$ for $l=1, \ldots, 5$.

While Table 2, shows a comparison between the computed least square errors of HPM and successive approximation method (SAM) which is discussed by many authors for different purposes. The results in the table show that our results are considerable accurate as it has less error than that of successive approximation method.

Table1. The absolute errors of example 1

$$
\text { for } \widehat{u}_{1,10}(x) \text { and } \widehat{u}_{2,10}(x)
$$

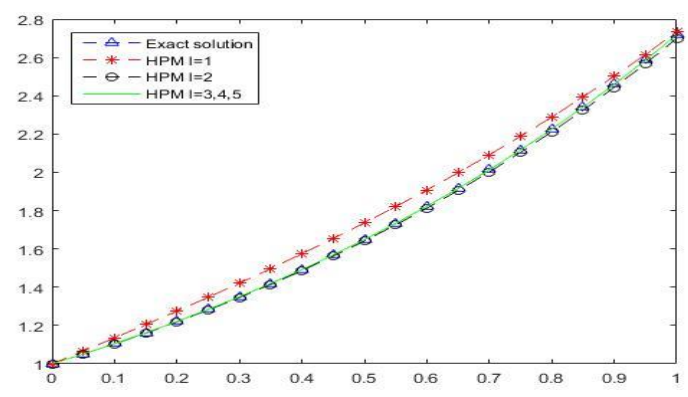

a. Graph of $u_{1}(x)=e^{x}$

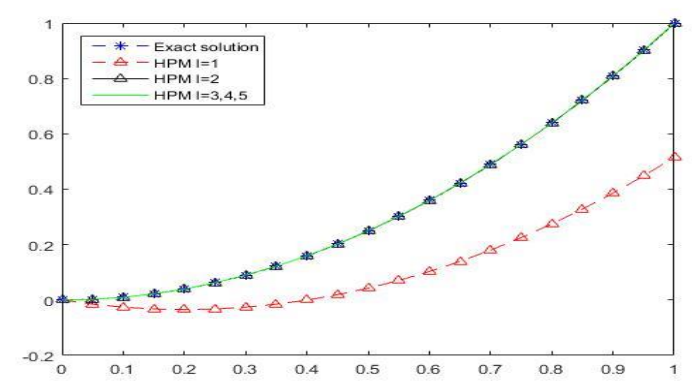

b. Graph of $u_{2}(x)=x^{2}$

Figure1. Graphs of the exact and numerical solution $(l=1,2, \ldots, 5)$ of example1 
Table2. A comparison between HPM and SAM (successive approximation method), for example 1 , with different values of $\boldsymbol{n}$.

\begin{tabular}{ccccc}
\hline & \multicolumn{2}{c}{ L.S.E of $u_{1}$} & \multicolumn{2}{c}{ L.S.E of $u_{2}$} \\
\cline { 2 - 5 }$n$ & HPM & SAM & HPM & SAM \\
\hline & & & & \\
3 & $8.00 \mathrm{e}-$ & $3.66 \mathrm{e}-03$ & $5.99 \mathrm{e}-$ & $\begin{array}{c}2.61 \mathrm{e}- \\
04\end{array}$ \\
& 08 & & 06 & 04 \\
6 & $3.01 \mathrm{e}-$ & $3.93 \mathrm{e}-09$ & $8.16 \mathrm{e}-$ & $1.23 \mathrm{e}-$ \\
& 13 & & 17 & 08 \\
9 & $2.01 \mathrm{e}-$ & $8.18 \mathrm{e}-15$ & $1.20 \mathrm{e}-$ & $1.38 \mathrm{e}-$ \\
& 20 & & 19 & 14 \\
1 & $9.81 \mathrm{e}-$ & $1.45 \mathrm{e}-20$ & $3.57 \mathrm{e}-$ & $2.88 \mathrm{e}-$ \\
2 & 27 & & 27 & 20 \\
\hline
\end{tabular}

Example 2. Consider the linear system of VolterraFredholm integral equations

$$
\left.\begin{array}{c}
u_{1}(x)=\cos (x)-\left(\frac{\pi^{2}+4}{256}\right) x^{2}+\frac{\pi}{32} x+ \\
\frac{1}{8} \int_{0}^{x} \int_{0}^{\frac{\pi}{2}}(r t-1) u_{2}(t) d t d r \\
u_{2}(x)=\sin ^{2}(x)-\frac{x^{2}}{16}+\left(\frac{\pi-2}{16}\right) x+ \\
\frac{1}{8} \int_{0}^{x} \int_{0}^{\frac{\pi}{2}}(r-t) u_{2}(t) d t d r \\
0 \leq x \leq \frac{\pi}{2}
\end{array}\right\}
$$

with the exact solutions

and

$$
u_{1}(x)=\cos (x)
$$

$$
u_{2}(x)=\sin ^{2}(x)
$$

Since $n \beta(b-a)^{2}=0.96895<1$,

Then, we let $u_{10}=f_{1}(x)$, and $u_{20}=f_{2}(x)$.

Thus, the continuous functions

$$
u_{1,0}{ }^{*}(x) \text { and } u_{2,0}{ }^{*}(x) \text { are selected in the }
$$

interval $\left[0, \frac{\pi}{2}\right]$ as explained in equation (9)

$$
\text { and } \begin{aligned}
u_{1,0}{ }^{*}(x) & =u_{10}(x) \\
& =\cos (x)-\left(\frac{\pi^{2}+4}{256}\right) x^{2}+\frac{\pi}{32} x \\
& =u_{20}(x) \\
& =\sin ^{2}(x)-\frac{x^{2}}{16}+\left(\frac{\pi-2}{16}\right) x
\end{aligned}
$$

then by the above technique the approximate solution $\hat{u}_{1 l}(x)$ and $\hat{u}_{2 l}(x)$ can be taken as

$$
\widehat{u}_{1 l}(x)=\sum_{j=0}^{l} u_{1 j}^{*}(x)
$$$$
\text { and } \quad \hat{u}_{2 l}(x)=\sum_{j=0}^{l} u^{*}{ }_{2 j}(x)
$$

The absolute errors for the exact solutions $u_{1}(x), u_{2}(x)$ and the approximate solutions $\widehat{u}_{1,10}(x), \widehat{u}_{2,10}(x)$ are presented in Table 3 , while Fig. 2 shows the convergence of the method for $\widehat{u}_{1, l}(x)$ and $\widehat{u}_{2, l}(x)$ for $l=1, \ldots, 5$.

Table 3: Absolute errors for $\hat{u}_{1,10}(x)$ and $\widehat{u}_{2,10}(x)$ of example 2 .

\begin{tabular}{ccc}
\hline$x_{j}$ & $\begin{array}{l}\text { Absolute error } \\
\text { of } u_{1} \mid u_{1}\left(x_{j}\right)-\end{array}$ & $\begin{array}{l}\text { Absolute error } \\
\text { of } u_{2} \\
\end{array}$ \\
& $\begin{array}{c}\left|u_{1,10}\left(x_{j}\right)\right| \\
-\widehat{u}_{2,10}\left(x_{j}\right) \mid\end{array}$ \\
\hline & & 0 \\
$0.1(\pi)$ & $7.4273920347 \mathrm{e}-14$ & $4.0259462430 \mathrm{e}-14$ \\
$0.2(\pi)$ & $1.2456702336 \mathrm{e}-13$ & $6.4281913126 \mathrm{e}-14$ \\
$0.3(\pi)$ & $1.5143442056 \mathrm{e}-13$ & $4.1942451996 \mathrm{e}-14$ \\
$0.4(\pi)$ & $1.5415446697 \mathrm{e}-13$ & $6.3615779311 \mathrm{e}-14$ \\
$0.5(\pi)$ & $1.3306891320 \mathrm{e}-13$ & $3.8857805862 \mathrm{e}-14$ \\
& & \\
\hline
\end{tabular}

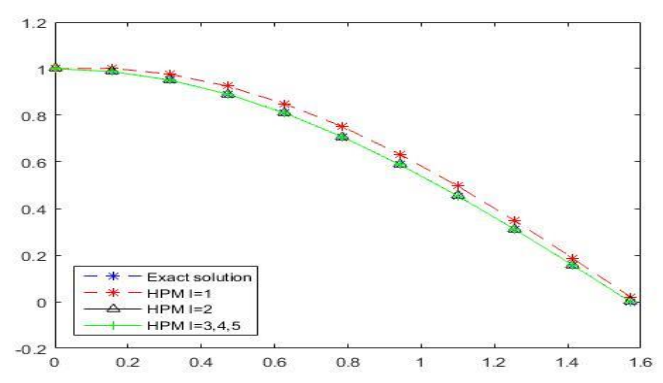

a. Graph of $u_{1}(x)=\cos (x)$

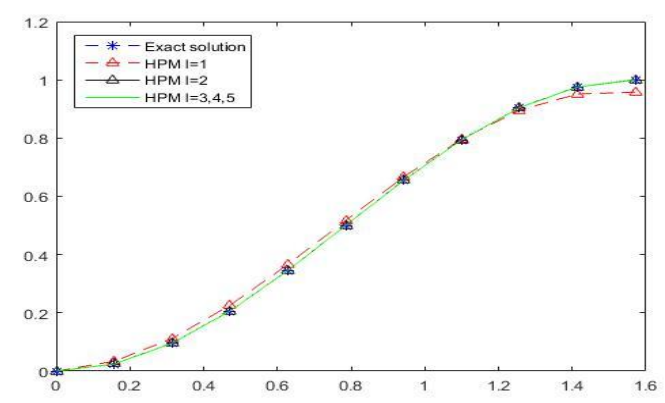

b. Graph of $u_{2}(x)=\sin ^{2}(x)$

Figure2: Graph of the exact and numerical solution $(l=1,2, \ldots, 5)$ of example 2 
Note: To show the error estimation in case there is not exact solution, consider the following example: Example3. Consider the linear system of VolterraFredholm integral equations

$$
\left.\begin{array}{c}
u_{1}(x)=f_{1}(x)+ \\
\frac{1}{6} \int_{0}^{x} \int_{0}^{1} k_{11} u_{1}(t) d t d r+\frac{1}{5} \int_{0}^{x} \int_{0}^{1} k_{12} u_{2}(t) d t d r, \\
u_{2}(x)=f_{2}(x)+ \\
\frac{1}{5} \int_{0}^{x} \int_{0}^{1} k_{21} u_{1}(t) d t d r+\frac{1}{7} \int_{0}^{x} \int_{0}^{1} k_{22} u_{2}(t) \cdot d t d r . \\
0 \leq x \leq 1
\end{array}\right\}
$$

Where

$$
\begin{aligned}
& f_{1}(x)=2 x+\frac{x^{2}-x}{60}+\frac{257 x^{3}}{270}, \\
& f_{2}(x)=\frac{281 x^{2}}{280}-\frac{x(26 x-75)}{300}-x, \\
& k_{11}=r^{2} x, k_{12}=r-x, \quad k_{21} r x-1,
\end{aligned}
$$

and $k_{22}=r x^{2}$.

Where, the exact solution is not given.

First, it will be verified whether the inequality (11) satisfied or not.

In this example, we have

$$
\begin{aligned}
& n \beta(b-a)^{2}=2(0.2)(1)=0.4<1, \\
\beta & =\max _{i=1,2, \ldots, n}\left\{\left|\lambda_{i j}\right| \cdot\left(M_{i j}\right)\right\}, \text { for } j=1,2, \ldots, n \\
= & 0.2
\end{aligned}
$$

Thus, by theorem 3.1, there exists a unique solution for the system.

Now to find the error estimation in theorem 3.2, we have

$$
\begin{aligned}
\varepsilon_{i l} & =\sup _{x \in[a, b]}\left|u_{i}(x)-\hat{u}_{i l}(x)\right| \\
& \leq L \frac{n^{l+1} \beta^{l+1}\left((b-a)^{2}\right)^{l+1}}{1-n \beta(b-a)^{2}}, \text { for } i=1,2
\end{aligned}
$$

Since, $f_{i}(x)$ are bounded for each $i=1,2$, then there exists $L_{i 0}$ such that

$$
\begin{aligned}
& \left|f_{i}(x)\right| \leq L_{i 0}, \forall x \in[a, b], \\
L_{10}= & \max _{x \in[0,1]}\left|f_{1}(x)\right| \\
= & \max \{0,2.951985\}=2.95185, \\
L_{20} & =\max _{x \in[0,1]}\left|f_{2}(x)\right| \\
& =\max \{0,0.166905\}=0.166905,
\end{aligned}
$$

Thus,

$$
L=\max _{i=1,2} L_{i 0}=2.95185 .
$$

Then for $i=1,2$; we have the estimated error of the 10th-order approximation will be

$$
\varepsilon_{i l} \leq(2.95185) \frac{(0.4)^{11}}{1-(0.4)}=2.063494 e-04
$$

While, for $15^{\text {th }}$-order, that is where $l=15$, we have

$$
\varepsilon_{i l} \leq(2.95185) \frac{(0.4)^{16}}{1-(0.4)}=2.113018 e-06
$$

Finally, for $20^{\text {th }}$-order, the error estimation becomes

$$
\varepsilon_{i l} \leq(2.95185) \frac{(0.4)^{21}}{1-(0.4)}=2.637303 e-08
$$

In Table 4 , for $i=1,2$, different orders of approximation with the corresponding error estimations are presented for example 3 .

Table: 4 Results of different values of $l$, and the corresponding values of $\varepsilon_{i l}, i=1,2$.

\begin{tabular}{cc}
\hline$l$ & $\varepsilon_{i l} \leq$ \\
\hline 3 & 0.215944320000 \\
6 & 0.008060436480 \\
9 & $5.15867935 \mathrm{e}-04$ \\
12 & $3.30155478 \mathrm{e}-05$ \\
15 & $2.11299506 \mathrm{e}-06$ \\
18 & $1.35231684 \mathrm{e}-07$ \\
21 & $8.65482777 \mathrm{e}-09$ \\
24 & $5.53908977 \mathrm{e}-10$ \\
27 & $3.54501745 \mathrm{e}-11$ \\
30 & $2.26881117 \mathrm{e}-12$ \\
\hline
\end{tabular}

\section{Conclusion}

In summary, the sufficient condition of convergence of the HPM for the LSMVFIE2 ${ }^{\text {nd }}$ is formulated and proved; an estimation of error is also given. HPM is discussed for solving the system and two examples are presented for illustration. Good approximations are obtained while better results have been found by increasing the number of components of the partial sum $(l)$. Moreover, a comparison between exact solution and its approximation made to demonstrate application technique. It is worth mentioning that the technique can be used as a very accurate algorithm for solving LSMVFIE $2^{\text {nd }}$. These claims are supported by the results of the given numerical examples in Tables (1-4) and Figures (1-2).

\section{Authors' declaration:}

- Conflicts of Interest: None.

- We hereby confirm that all the Figures and Tables in the manuscript are ours. Besides, the Figures and images, which are not ours, have been given 
the permission for re-publication attached with the manuscript.

- The author has signed an animal welfare statement.

- Ethical Clearance: The project was approved by the local ethical committee in University of Salahaddin.

\section{Reference}

1. Ghasemi M, Fardi M, Ghaziani RK. Solution of system of mixed Volterra-Fredholm integral equation by an analytic method. Math Compute Model. 2013; 58 (78):1522-1530.

2. Karimi S, Jozi M. Numerical solution of system of linear Fredholm integral equations based on Degenerate Kernels. TWMS J. Pure Appl. Math. 2015;-111:(1)6 119.

3. Wazwaz AM. A First course in integral equations. Second Edi. Saint Xavier University, USA: world scientific Publishing Co. Pte. Ltd.; 2015 (50-55).

4. Alturk A. Numerical solution of linear and nonlinear Fredholm integral equations by using weighted meanvalue theorem. Springer Plus. 2016; 5:1962. 1-15.

5. Mirzaee F. Numerical solution of integral equation via improvement of block-pulse function. J. Math Model . 2016-133:(2)41.59

6. Hesameddini E, Shahbazi M. Solving system of Volterra Fredholm integral equations with Bernstein polynomials and hybrid and hybrid Bernstein block pulse functions. J Comput Appl Math. 2017; 315:182-194.

7. Farhana NZ, Radzuan M, Suardi MN, Sulaiman J. Numerical Solution of System of Second Kind Fredholm Integral Equations Using Four-Point Explicit Group Successive Over Relaxation Iteration. Adv Sci Lett. 2018 Mar 1;24(3):1736-40..

8. Hameed HH, Eshkuvatov ZK, Nik Long NMA. On solving an $n \times n$ system of nonlinear Volterra integral equations by the Newton-Kantorovich method. Sci. Asia. 2016; 42S (1):11-18.

9. Eshkuvatov ZK, Hameed HH, Taib BM, Long NN. General $2 \times 2$ system of nonlinear integral equations and its approximate solution. J. Comput. Appl. Math.. 2019 Dec 1;361:528-46.

10. He JH. Homotopy perturbation technique. Compute methods Appl Mech Eng. 1999; 3-4(178): 257-262.

11. He JH. coupling method of homotopy technique and perturbation method for nonlinear problems. Int. $\mathbf{J}$ non Linear Mech. 2000; 35(1):37-43.

12. He JH. Homotopy perturbation method: a new nonlinear analytical technique. Appl. Math. Comput. 2003; 135(1):73-79.

13. Jafari H, Alipour M, Tajadodi H. Convergence of homotopy perturbation method for solving integral equations. Thai J Math. 2010; 8(3): 511-520.
14. Biazar J, Eslami M. Exact solutions for nonlinear Volterra-Fredholm integro-differential equations by He's homotopy perturbation method. Int. J non linear Sci. 2010; 9(3):285-289.

15. Biazar J, Ghanbar B, Porshokohi MG. He's homotopy perturbation method: A strongly promising method for solving nonlinear system of mixed VolterraFredholm integral equations. Comput. Math. with Appl. 2011; 61(4): 1016-1023.

16. Mirzazadah M, Ayati Z. New homotopy perturbation method for system burger equation. Alexandria Eng. J. 2016: 55(2):1619-1624. 


\section{تحليل التقارب لطريقة الاضطراب Homotopy لنظام خطي من معادلات فولتيرا - فريدهولم التكاملية المختلطة من النوع الثاني مئ مين}

$$
\text { نجم ألاين عبد الله سليمان }
$$

$$
\text { به خشان محمد أمين حسن }
$$

قسم الرياضيات-كلية التزبية-جامعة صلاح الدين-أربيل-ألعراق.

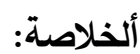

في هذه الورقة ، تم تقديم طريقة اضطر باب homotopy لحل نظام خطي من معادلات فولنتيرا ـ فريدهولم التكاملية المختلطة

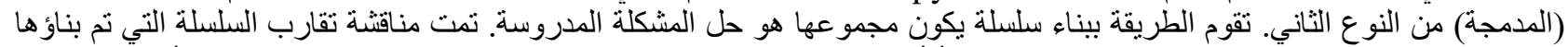

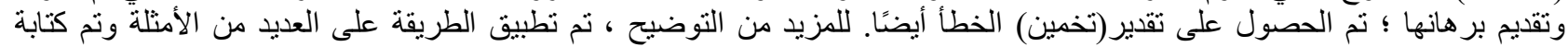

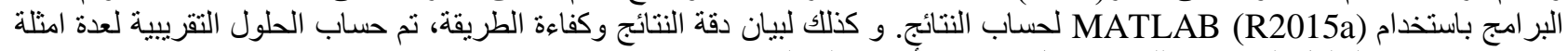
ومن ثم مقارنتها بالحلول الحقيقية وذلك من خلال حساب الأخطاء المطلقة.

الكلمات المفتحية: طريقة اضطراب homotopy، نظام خطي من معادلات فولتيرا - فريدهولم النكاملية المختلطة من النوع الثاني. 